\title{
VERS: Practical Digital Preservation
}

\section{Howard S. Quenault}

\author{
Public Record Office Victoria \\ 99 Shiel Street, \\ North Melbourne, \\ Victoria, \\ Australia \\ howard.quenault@dpc.vic.gov.au
}

\begin{abstract}
The Victorian Electronic Records Strategy, better known as VERS, is a practical method for the long-term preservation of digital records. From its inception in 1995 through to today, the VERS program has been a collaborative effort between the Victorian State Government, Industry and Academia to develop and promulgate standards, policies and technologies to support the effective capture, management and preservation of digital records.

RÉSUMÉ. La stratégie d'archivage électronique de Victoria, plus connue sous le nom de VERS, est une méthode pragmatique pour la conservation à long terme des documents électroniques. Depuis son démarrage en 1995 jusqu'à aujourd'hui, le programme VERS a bénéficié d'une collaboration efficace entre le gouvernement de l'Etat de Victoria, le monde industriel et le milieu universitaire pour développer et adopter des normes, des principes directeurs et des technologies pour la capture, la gestion et la conservation des archives numériques.
\end{abstract}

KEYWORDS: recordkeeping VERS digital preservation strategy.

MOTS-CLÉS : archivage, VERS, stratégie de conservation numérique.

$\mathrm{DN}-8 / 2004$. Archivage et pérennisation, pages 23 to 35 


\section{Introduction}

The late 20th century saw a sea change in the methods available for human communication. From a world based on face-to-face and written, delayed, communication, we have moved into a world increasingly dominated by non paperbased new technologies and instantaneous or near-instantaneous communication systems, such as e-mail.

This has meant that an increasing amount of business and government activity is now conducted digitally. Information that once would have been hand-or typewritten and stored in paper files is generated, managed and manipulated on computer systems. This trend has accelerated in the past five years, with a preponderance of information now being produced in a digital form. Performing work, communicating with citizens, and managing information digitally poses a new set of challenges for government.

The Victorian Government in Australia intends that all Victorians share in the benefits of the digital age and the potential for increased access to services that it brings. However, to fully engage with confidence in the digital environment, citizens, businesses and government agencies need confidence that their transactions will be safe, secure, and remembered in a sustainable way, despite the vagaries of the software market or changing hardware formats.

To deal with the issues surrounding digital record preservation the Victorian Government has developed and endorsed the Victorian Electronic Records Strategy (VERS).

VERS represents a proactive and innovative approach to a global problem. From the original VERS project in 1995-96 to the current operations of the VERS Centre of Excellence at Public Record Office Victoria (PROV), VERS has grown to be a world-leading digital recordkeeping solution.

Digital records prove challenging for government agencies, archives, and business, especially when those records are required to be maintained for the long term. Such records cause problems because:

- digital formats change rapidly and become obsolete;

- digital systems also become obsolete over time;

- digital documents can often be changed without detection;

- the context of a record, and its relation to other records, can easily be lost, especially when those records are removed from the system that created them;

- existing systems for managing digital records are not designed for long term preservation.

Many digital documents are created in an ad hoc fashion and are not usually well managed, being stored mostly on network hard drives, personal hard drives or in email systems. This leads to the problem in many organisations of the presence of 
large amounts of stored data about which very little is known. It can also lead to the familiar problem of having to re-do or re-invent business processes because no one in the organisation is aware of what has happened in the past. The corollary to this is the inability of any organisation to properly control the digital information it holds or creates. The privacy of individuals cannot be ensured in the digital age without a system to manage digital information, a problem that is of concern to lawmakers worldwide.

These are issues of increasing importance for all organisations that do business digitally, but the problem has extra dimensions for government. Not only is current information compromised, because it is insecure, untrustworthy or simply irretrievable; the long-term status of information is questionable. Documents created with proprietary software will be unreadable within a foreseeable time: certainly, they will not be capable of retention "forever". The cultural heritage of the polity, as well as the personal and public interest information contained in government documents that are "born-digital", therefore cannot be preserved or secured in an unmanaged system. Government cannot deliver open, accountable, and ethical government if it can neither demonstrate its actions nor guarantee the security of citizens' private information.

Furthermore, waiting for the marketplace to deliver a solution is not a practicable alternative for government. The initial research project, Keeping Digital Records Forever (1995/96), suggested that assigning the risk of innovation to the private sector was one possible path:

"It could be asked - 'Why should the Government adopt the project's recommendations and why should it take the risks? As this problem is universal in the digital community, someone is likely to find a solution soon, thereby saving the Government development costs. When the commercial community has solved the problem, then we'll buy the working product."

In 2004, the private sector and software marketplace has still not arrived at a working solution, or even several possible solutions. The initiative taken by the Victorian Government in researching and designing VERS is largely unmatched in its practicality, cost-effectiveness and efficiency.

This is a problem that can be neither ignored nor put aside for the future. Unlike paper records, digital records are intrinsically fragile from "birth":

"Unlike paper archives, digital archives can not be left or neglected for any period without records being permanently lost."

What this means is that without the adoption of a shared solution across the government, permanent records of the State of Victoria will be lost forever. The consequences are considerable:

- Erosion of the Government's accountability to the Victorian community; 
- Loss of information that the State may require as proof of its activities in the event of a legal dispute;

- Loss of irreplaceable segments of Victoria's history and heritage;

- Non compliance with relevant legislation including the:

- Freedom of Information (Amendment) Act 1993 under which agencies need to be able to supply documents to the public including born-digital records on request,

- Public Records Act 1973 under which public records that are assessed as permanent by PROV must be able to be retained and read forever,

- Information Privacy Act 2000 under which the Government must be able to protect the privacy of individuals which involves secure, reliable controlled access to records;

- Health Records Act 2001 under which organisations providing health services must be able to appropriately manage patient information indefinitely;

- Electronic Transactions Act 2000 which aims to support and encourage ecommerce and e-business, in part by ensuring the long-term and reliable maintenance of records of e-transactions.

Victoria therefore needs a holistic, robust, cost-effective method of managing, preserving and accessing digital records into the foreseeable future. The Victorian Electronic Records Strategy (VERS) is that solution.

\section{The Solution - The Victorian Electronic Records Strategy}

An innovative and world-leading program, VERS addresses the important question of keeping digital records for the long-term - preserving vital data in spite of quickly changing software, formats and computing technology. Public Record Office Victoria, the state's archives, has worked with industry and science partners over the last 8 years to develop the strategy as an effective and practical solution. VERS will help the government to confidently secure, manage and preserve its digital records, a crucial part of supporting the move to a sophisticated governmentcitizen e-relationship.

VERS is an application independent strategy that allows for the capture, authentication and long-term preservation of digital records. It is an integrated program of technologies, consultancy, policies and standards.

Central to the approach is the VERS Standard, a three-part solution for preservation of electronic records:

- Encapsulation into a single long term format:

One or more documents are "bundled" together with a detailed set of metadata which holds information about the documents (such as when, where, how, and by 
whom the document or documents were created). The metadata is stored using XML (extensible mark-up language) format, which forms a wrapper both around the documents and for the record itself.

\section{- Use of Long Term Preservation Formats:}

Digital documents (generated by software such as Microsoft Word) are converted to a long-term format (PDF or TIFF). These formats were chosen because it is expected that in the future it will provide the best chance that an attempt to read the document will be successful (that is, a person will be able to view the document in its original form). Unlike Microsoft Word, which is a proprietary format, PDF and TIFF formats are published standards and are therefore likely to remain readily available to read files. With current developments in relation to the development of an international standard for portable document format, PDF/A (PDF for Archiving) there is even more likelihood of being able to access documents over the long-term in a predictable manner.

- Digital Signature:

A public-key digital signature is attached to the "bundle" of documents, providing a 'seal' for the record, increasing the integrity and authenticity of each electronic document as it is preserved. The product of this process is known as a VERS Encapsulated Object (VEO).

A digital record, in the form of a VEO, is a single text object that can easily be transmitted and accessed by a text editor. It has substantial business value in terms of interoperability, authenticity, accessibility and integrity and it can be used as the basis of business accountability, risk management and information exchange for now and into the future.

The VERS strategy is underpinned by the VERS Standard (PROS 99/007). The standard contains detailed technical information about the type of system and functionality required to be able to create and manage VEOs, the metadata fields required, and the exact specifications for how the XML, Long term preservation formats, and digital signatures should be fitted together to form a VEO.

Guidance on the strategy is supported by an extensive training program, the VERS web site ${ }^{1}$, VERS web toolkit, agency advice and consultancy assignments.

VERS is mandated as the Victorian Government response to the problem of digital recordkeeping via PROV's legislative ability to set standards for the public sector.

VERS has already been accepted as the way forward for digital recordkeeping in Victoria, with several departments progressing towards full implementation and key integration of VERS with all e-Government policies and projects. An established,

1. http://www.prov.vic.gov.au/vers 
practical, cost-effective solution, VERS is recognised globally as a leading digital records solution model.

\section{VERS Projects}

\subsection{Stage 1 Investigation of the Problem}

In the initial project investigations the consultants retained found that no adequate solution existed worldwide to the problem of keeping digital records in an accessible, contextualised format for the long-term. Until then, most recommendations had centred on the migration of data to new applications, an approach the Keeping Electronic Records Forever $^{2}$ team rejected. They charged PROV with finding an application-independent solution that could create "snapshot" records, complete with their context: records that would meet the key criteria of authenticity, accessibility and comprehensibility, and would be capable of being read in the long term.

\subsection{Stage 2 VERS Strategy Formulation}

In 1997/98 PROV was tasked to find an application-independent solution that could create 'snapshot' records, complete with their context. These 'snapshot' records would be required to meet the key criteria of authenticity, accessibility and comprehensibility and would be capable of being read in the long term. The VERS project team was subsequently formed and was composed of representatives from PROV, the CSIRO (Commonwealth Scientific and Industrial Research Organisation) and business consultancy Ernst \& Young. The team completed its work in 1999 and published a Final Report, which included recommendations on the structure of a long-term digital records preservation strategy for Victoria.

\subsection{Stage 3 VERS Pilot Strategy}

In 1999, the Department of Infrastructure (DOI) was selected to implement a VERS-compliant recordkeeping solution as a whole of Victorian government pilot. It is now in the process of utilising the capability across the department to capture digital records into a production digital records repository. Digital records appraised as having permanent value will be able to be transferred to the PROV Digital Archive when this is available in 2005.

DOI has made the intellectual property created in the course of this project, including some software, available to other agencies as they embark on their

2. http://www.prov.vic.gov.au/vers/published/kerf.htm 
implementation of the VERS solution. As part of the adoption of the VERS standard across the rest of Victorian government the department will provide ongoing advice and mentoring to other implementations across government, streamlining processes and bringing the government into a VERS-compliant network.

\subsection{Stage 4 VERS Centre of Excellence \& VERS Digital Archive}

The current VERS project has seen the establishment of a VERS Centre of Excellence. The Centre consists of a team of digital record professionals with a wide range of practical experience in implementing VERS projects. In addition, the Centre is overseeing the development of a central Digital Archive located within Public Record Office Victoria to house and provide access to digital records of Victorian Government.

The Centre has developed a comprehensive set of tools and implementation guides to aid the development of agency implementation strategies and implementations themselves. These are available on the online VERS implementation Toolkit ${ }^{3}$.

\section{VERS adoption within Victorian Government Agencies}

We have found that planning and implementing improvements to digital records management is a long-term prospect. Based on our experience, adoption of VERS within departments is being conducted over a number of stages.

\subsection{Stage 1-Deploy Primary Capability (1-3 years'duration)}

Deploy a primary capability (for example a VERS compliant Electronic Document Management (EDM) or Electronic Records Management (ERM) system) which will deliver value to the organisation as a solution to basic EDM/ERM requirements and as a platform for future leverage. This may also include one or two business process automation initiatives.

\subsection{Stage 2 - Deploy to Key Business Processes (3+ years'duration)}

After the initial basic implementation, begin to focus on the organisation's high value, permanent value and long term temporary records needs. Gain an understanding and define the core business processes (or applications) that would

3. http://vers.imagineering.com.au/ 
benefit from improved records management requirements and records capture automation.

\subsection{Stage 3 - Deploy Enterprise-wide (5+ years' duration)}

Deploy remaining processes as an enterprise solution for digital records management. This may include support for advanced capabilities such as interdepartmental process integration and automation, or digital record discovery through the Victoria Online portal. For example, the potential to offer consistent archiving and retrieval of Lotus Notes email into the medium to long-term may be offered via VERS.

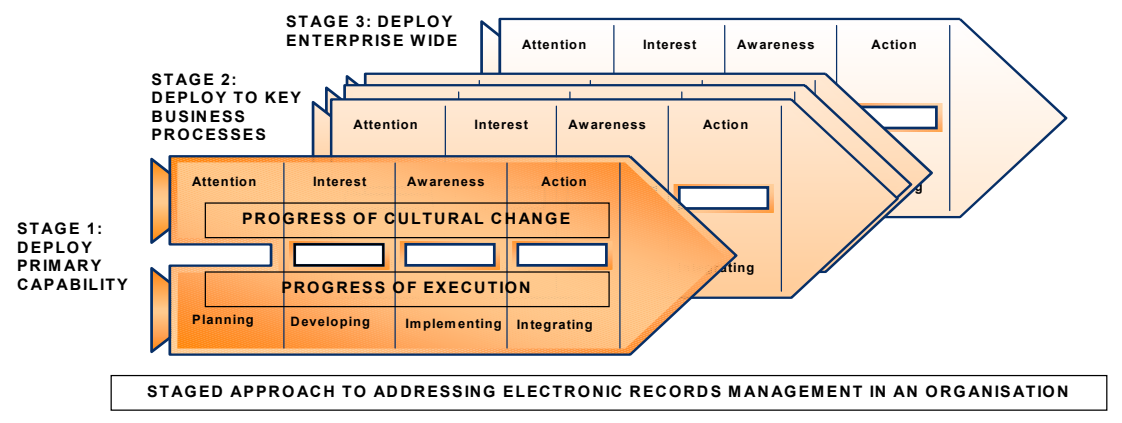

Figure 1. Deploying VERS

All departments are currently at differing phases of Stage 1 - primary capability deployment and will require continuing assistance from the VERS Centre of Excellence as they progress to stages 2 and 3 .

To sustain the continued adoption, implementation and compliance of VERS, agencies will require continuing expert advice on the VERS standard and implementation models. It has been found that VERS can be adopted in the operational environment of agencies using a number of different models:

- At the most basic level the agency can implement a desktop programme and capture its key permanent digital records in a VERS format and transfer these to PROV;

- A more sophisticated approach is to implement a document/records system or content management system that provided the ability to capture and manage digital records which can then be transferred, in a VERS format, to PROV. In this case, line of business (LOB) applications pass their digital records to the records system for management and transfer of the record rather than all the LOB applications being VERS compliant themselves; 
- Another approach is to engage a third party provider to extract digital records from a current line of business application and return the encapsulated VERS records to the agency for subsequent transfer to PROV;

- In some agencies it will be necessary to provide an interim VERS compliant archive for those long-term temporary records that need to be kept for between 2090 years. (Example child welfare case files or personnel files.) In this case the agency will need to consider implementing VERS software infrastructure to provide this capability.

To maximise the potential for departments to successfully adopt VERS the VERS Centre delivers support services covering the following:

- Strategic Consultancy,

- VERS expertise (on call) to support all project phases,

- Provision of Advice and Guidance on all aspects of digital records, benefit,

- Undertaking Research on digital preservation providing a whole of government

- Access to VERS Intellectual Property developed as part of the program,

- Training on all aspects of VERS (Business, Technical and End-User),

- Supporting Software and Services Vendors to deliver more products to the marketplace through the certification process,

- Ensuring that VERS keeps abreast of developments in National and International Standards,

- Annual Departmental VERS readiness assessment.

\subsection{Ongoing external factors affecting implementation}

To sustain the implementation of VERS within Government a number of external factors need to receive continued attention.

- The need for ongoing VERS compliance testing and approval of vendor products,

- The requirement for a sustainable market for VERS compliant products,

- The correct positioning of VERS in the Government's overall information management agenda,

- Ensuring best practice electronic record keeping through research and development. 


\subsubsection{The Need for Ongoing VERS Compliance Testing and Approval of Vendor Products}

The Centre of Excellence has implemented a VERS compliance testing process for commercial software products in which eleven vendors are currently participating.

In addition, it is important for relationships to be maintained with vendors to encourage the availability of software products to cover different user requirements so that the penetration of VERS is as broad as possible. For example, it is valuable to have products in the desktop, line of business, document management systems, records management systems and enterprise content management systems VERS compliant.

\subsubsection{Building a Sustainable Market for VERS Compliant Products}

To make the entry level for VERS adoption simple and cost effective it is critical to get as many commercial software products as possible VERS compliant.

PROV has developed a mandated standard for digital records (PROS 99/007) for application by all agencies. As more agencies seek to adopt the VERS standard this will encourage commercial vendors to build the standard into their products and thus help to create a more sustainable marketplace for VERS. To further assist this process, the requirement for VERS compliance in being built onto the agency procurement process.

There is potential for VERS to be adopted by commercial organisations, Australian States and internationally thus establishing a sustainable market. This will require continued engagement of government, research and commercial organisations both at a local, national and international level to develop the VERS approach and standard.

\subsubsection{Positioning VERS in the Overall Government Information Agenda}

PROV is developing relationships with the Office of the Chief Information Officer to position recordkeeping in the Government's information management agenda. Digital recordkeeping does not standalone and requires continued attention to ensure that the linkages to other strategic initiatives in government are fostered.

Digital records within agencies are created in the operational environment most commonly associated with the information management and information technology domains. It is crucial to ensure that digital records thinking and application is applied to the strategic objectives within these domains.

\subsubsection{Ensuring Best Practice in Electronic Records Management}

To ensure best practice in digital records management there will be a continuing need to liaise with research, academia, state archives, international archives and 
commercial organisations to ensure that advances within the field of digital records are tracked, developed and communicated to agencies and Government.

\section{Digital Archive Model}

With the increased uptake of VERS throughout the Victorian Government, agencies will be producing more and more VERS compliant digital records as part of normal business processing. As agencies finish using the records in their day to day work, digital records of permanent value will be transferred to PROV as part of agency's records disposal program. These records will be transferred in a VERS encapsulated format (VEO). PROV must be ready to receive transfers of these VEOs and to preserve them for the long-term within the Digital Archive.

In the PROV Digital Archive model, the following definitions are used.

- Digital Archive: A Digital Archive relates to a system, including technical infrastructure, standards, policies and procedures, for managing and providing access to digital objects and their associated metadata.

- Digital Repository: A Digital Repository relates to the component of the Digital Archive that provides storage of the digital objects and their metadata.

The PROV Digital Archive will manage and preserve permanent VEOs of the Victorian Government, and will enable online access to these digital records. The access component to the PROV Digital Archive will also provide user access to the metadata for paper collections at PROV.

The PROV Digital Archive will include a Digital Repository component. The Digital Repository will be a storage system to house digital objects, specifically born-digital records (which might have been created as word processing documents, spreadsheets, emails, databases, websites etc) and digitised copies of paper records in the form of VEOs.

\section{Functional Design Overview}

Digital Archive Domain

The PROV Digital Archive consists of six mega-functions: Records Transfer, Records Storage, Records Access, Data Management, Administration and Management.

\section{Digital Repository Domain}

The domain 'Digital Repository' has a more narrow focus, referring to the actual storage of the VEOs and the management of the metadata associated with VEOs. 
The PROV Digital Repository consists of the mega-functions Records Storage and Data Management.

\section{Records Transfer Function}

Covers the transfer of permanent VEOs and associated metadata from agencies to the PROV Digital Repository. VEOs undergo virus checking and quality assurance testing as part of the transfer process.

\section{Records Storage Function}

Covers the ongoing physical maintenance of VEOs within the Digital Repository, including storage, media management and security. It includes comprehensive mechanisms (relating to backup, high availability and disaster recovery) to ensure that records are never lost. Record Storage also covers all operational activities carried out on VEOs by PROV staff.

\section{Data Management Function}

Covers the management of the metadata associated with the VEOs. It includes the processes of updating the repository with new metadata, maintaining the metadata, querying the data and providing responses to queries. Data Management also covers all operational activities carried out on VEO metadata by PROV staff.

\section{Records Access Function}

Covers the provision of online access to records in the PROV collection (paper and digital) to PROV Users. This includes browsing, searching, ordering and viewing records and descriptive metadata. For paper records, access refers to the ability to search or browse descriptive metadata about records, and to order the records. For digital records, access also covers the ability to search or browse metadata about the records as well as viewing VEOs.

\section{Administration Function}

This element covers the administrative tools needed to manage the PROV Digital Archive components and the system as a whole. This includes generic system administration activities, as well as security, audit, back-up and restore, disaster recovery, virus checking and queries and reports.

\section{Management Function}

This element covers management components of the PROV Digital Archive, including appraisal, disposal, managing transfers. It also covers the development of standards, policy and procedures and providing training.

The Records Transfer, Records Storage and Data Management, Administration and Management mega-functions of the PROV Digital Archive will manage and 
preserve only the digital records (VEOs) in the PROV collection. The Records Access element of the PROV Digital Archive however will provide online access to all records in the PROV collection, both paper and digital, though a single interface.

\section{Conclusion}

With the development and implementation of the Digital Archive the last piece will fall into place in providing a practical infrastructure for the capture and management of digital records for the long-term. The continuing challenge is to make effective use of the infrastructure within the context of operational business requirements and constraints.

VERS offers the Victorian Government the opportunity to create its own digital heritage and, in so doing, move away from the digital dark ages.

\section{References}

Keeping Electronic Records, Public Record Office Victoria, Australia, 1996: www.prov.vic.gov.au/vers/published/kerf.htm

VERS Final Report, Public Record Office Victoria, Australia, 1998: http://www.prov.vic.gov.au/vers/published/final.htm

VERS Standard, PROS 99/007 Standard for the Management of Digital Records, Version 1.0, Public Record Office Victoria, Australia, 1999:

http://www.prov.vic.gov.au/vers/standards/standards.htm 